\title{
Características municipais determinantes da presença de diferentes prestadores de serviços de abastecimento de água no Brasil
}

\section{Municipal determinants of the presence of different water providers in Brazil}

Data de entrada: 09/08/2014

Data de aprovação: $17 / 11 / 2014$

Hygor Aristides Victor Rossoni / Marco Túlio da Silva Faria | Fernanda Fonseca Pessoa Rossoni / Sueli Aparecida Mingoti / Léo Heller

Resumo:

DOI: $10.4322 /$ dae.2014.144

O presente estudo busca explicar os motivos que levam os titulares - municípios - a optar por determinado modelo de gestão dos serviços de abastecimento de água, que foram agrupados em: administração direta municipal, administração indireta municipal, companhias estaduais de saneamento e empresas privadas. Para tanto, foram utilizados microdados obtidos pela compatibilização de três bancos de dados formados a partir da Pesquisa Nacional de Saneamento Básico, do Censo Demográfico e do Atlas do Desenvolvimento Humano, referentes aos anos de 2008, 2010 e 2013, respectivamente. Foram criados quatro indicadores e selecionadas 11 variáveis de estudo, com uma amostragem de 5.493 distritos-sede brasileiros. Os resultados foram obtidos por meio de testes estatísticos não paramétricos univariados, formados pela análise de variância e de comparações múltiplas, e multivariados, pela análise de correspondência. Observou-se que a natureza jurídica do prestador de serviço apresenta variações em relação às macrorregiões brasileiras, sendo que as empresas privadas possuem maior associação com a região Norte e as companhias estaduais de saneamento, com as regiões Nordeste e Sul. Constatou-se que as autarquias, seguidas pelas companhias estaduais de saneamento, atuam em cidades mais populosas e com o maior número total de economias abastecidas. O grupo formado pelas empresas privadas e pela administração direta municipal apresentou menor índice de inadimplência, sendo que essa característica das empresas privadas é provavelmente explicada pelo pressuposto de ganho financeiro visado pelo capital privado. É possível sugerir que os modelos de prestação de serviços de abastecimento de água adotados no Brasil estão relacionados a discrepâncias na implantação de políticas públicas pelo poder público e na resposta dada aos problemas sanitários pela população em função dos diferenciais regionais, socioeconômicos, demográficos, culturais e do contexto histórico e político do Brasil.

Palavras-chave: Políticas públicas. Saneamento. Gestão de serviços de abastecimento de água.

\section{Abstract:}

This paper intends to explain the reasons why the service holders - municipalities - choose a particular model of water services management, grouped in: Direct Municipal Administration, Indirect Municipal Administration, Regional Companies and Private Companies. Microdata from three databases were crossmatched: the 2008 National Survey of Basic Sanitation, the 2010 Demographic Census and the 2013 Atlas of Human Development. Four indicators were created and 11 variables were selected and were applied in a sample of 5,493 Brazilian municipalities. The results were obtained through nonparametric univariate tests, by analysis of variance and multiple comparisons, and multivariate models, by correspondence analysis. The legal nature of the service provider has variations among Brazilian regions; private companies have a greater association with the Northern region and regional companies with Northeastern and Southern regions. Indirect administration and, in second place, regional companies, operates in more populated cities and with the largest total number of connections. The group 
formed by private companies and by direct municipal administration presented the lowest default rate, and this characteristic of the private companies is probably explained by the assumption of financial gain. It was possible to suggest that the model for water provision adopted in Brazil is related to discrepancies in implementation of public policies by the government and to the reactions of the population to sanitary problems due to different regional, socioeconomic, demographic, cultural, historical and political context in Brazil.

Keywords: Public policy. Water supply. Management. Provision.

\section{Hygor Aristides Victor Rossoni}

Engenheiro ambiental e mestre em Ciência Florestal pela Universidade Federal de Viçosa (UFV). Doutorando do Programa de Pós-Graduação em Saneamento, Meio Ambiente e Recursos Hídricos (PPGSMARH) da Universidade Federal de Minas Gerais (UFMG). Professor do Instituto de Ciências Exatas e Tecnológicas do Campus Florestal da UFV.

\section{Marco Túlio da Silva Faria}

Tecnólogo em Gestão Ambiental pelo Campus Florestal da UFV. Graduando em Engenharia Ambiental pelo Centro Federal de Educação Tecnológica de Minas Gerais (CEFET-MG).

\section{Fernanda Fonseca Pessoa Rossoni}

Jornalista e mestre em Ciência Florestal pela UFV. Doutoranda do PPGSMARH da UFMG. Assessora de comunicação do Campus Florestal da UFV.

\section{Sueli Aparecida Mingoti}

Graduada em Estatística pela Universidade Estadual de Campinas. Mestre em Estatística pelo Instituto de Matemática Estatística e Ciência da Computação. Doutora em Estatística pela lowa State University of Science and Technology. Professora associada do Instituto de Ciências Exatas da UFMG.

\section{Léo Heller}

Engenheiro civil, mestre em Engenharia Sanitária e doutor em Epidemiologia pela UFMG. Pós-doutor pela Universidade de Oxford, Inglaterra. Professor titular do Departamento de Engenharia Sanitária e Ambiental da UFMG.

\section{Endereço para correspondência:}

Programa de Pós-Graduação em Saneamento, Meio Ambiente e Recursos Hídricos

Universidade Federal de Minas Gerais, Salas 4618 e 4619, $4^{\circ}$ andar do Bloco 1

Escola de Engenharia, Campus Pampulha - Avenida Antônio Carlos, 6627, CEP 31270-901

Belo Horizonte - MG - Brasil

E-mail: rossoniaufmg.br; rossoniaufv.br

\section{INTRODUÇÃO}

Em uma resolução histórica, a Organização das Nações Unidas (ONU, 2010) declarou o acesso à água potável e ao esgotamento sanitário como direito humano fundamental. Esse novo cenário, inquestionavelmente, requalifica os papéis dos agentes públicos e sociais que atuam no saneamento brasileiro.

Com o advento da Lei de Diretrizes Nacionais para o Saneamento Básico (LDNSB - Lei nº 11.445/2007), foi estabelecida a conceituação atualizada de saneamento básico, que não mais se restringe apenas ao abastecimento de água e esgotamento sanitário, incorporando, também, os serviços de limpeza urbana e o manejo de resíduos sólidos, bem como o manejo das águas pluviais. A partir desse enten- dimento, poderá haver maior incentivo para que os quatro componentes sejam gerenciados de forma integrada (MAGALHÃES, 2009).

Nos últimos anos, verificou-se certo avanço na cobertura dos serviços de saneamento básico no Brasil (CAMPOS; MONTENEGRO, 2011). Entretanto, conforme a Pesquisa Nacional de Saneamento Básico (PNSB), 12 milhões de domicílios do país ainda não têm acesso à rede geral de abastecimento de água (IBGE, 2010).

Conforme determina a LDNSB (BRASIL, 2007), os serviços públicos de saneamento básico devem ser prestados com base nos seguintes princípios fundamentais: universalização do acesso; integralidade; os serviços de saneamento devem ser 
realizados de forma adequada à promoção da saúde pública e à proteção do meio ambiente; disponibilidade em todas as áreas urbanas; adoção de métodos, técnicas e processos que considerem as peculiaridades locais e regionais; articulação com as políticas de relevante interesse social; eficiência e sustentabilidade econômica; utilização de tecnologias apropriadas; transparência das ações; controle social; segurança, qualidade e regularidade; e, por último, integração das infraestruturas e serviços com a gestão eficiente dos recursos hídricos.

Segundo Rezende e Heller (2008), as primeiras companhias de saneamento que atuaram no Brasil, a partir de meados do século XIX, eram privadas. Rio de Janeiro foi a cidade em que houve a primeira experiência privada no país, seguida das cidades de Recife, Porto Alegre, São Paulo, Belém, Maranhão e Fortaleza. Devido ao fato de grande parte das empresas não estar prestando os serviços adequadamente, o governo federal articulou politicamente a implementação de um modelo de administração indireta dos serviços de saneamento pelos municípios e alguns estados. Assim, na década de 1930, iniciou-se a implantação desse modelo, prioritariamente nas cidades de economia mais dinâmica e com maior população. $\mathrm{Na}$ década de 1950, esse modelo começou a ser criticado, principalmente em função do poder centralizador, da política tarifária inadequada e das dificuldades de arrecadação pela administração dos serviços.

Por outro lado, em 1952 foi criado o primeiro Serviço Autônomo de Água e Esgotos (SAAE), em Governador Valadares. Na década de 1960, esse modelo foi implantado em algumas cidades do Vale do Rio Doce, em Minas Gerais e no Espírito Santo (REZENDE, 2005).

Na década de 1970, o governo federal formulou o Plano Nacional de Saneamento (PLANASA), com a intenção de implementar o saneamento, princi- palmente o abastecimento de água, nas regiões mais industrializadas do país, as quais passavam por aumento demográfico em função do incremento das atividades econômicas e do êxodo rural. Como forma de exploração desses serviços, optou-se por privilegiar sua prestação por meio das companhias estaduais.

Com essas medidas, foram criadas e/ou adaptadas 27 companhias estaduais, que assumiriam as atividades de instalação, manutenção e operação do sistema de abastecimento de água e esgotamento sanitário. 0 mecanismo de ressarcimento das despesas na prestação do serviço, em um mecanismo de autossustentação financeira, seria feito por meio de cobrança de tarifas diferenciadas. De acordo com Sousa (2011), para conseguir a adesão dos municípios a esse programa, o governo federal vinculou o acesso aos principais recursos do setor à concessão dos direitos de exploração para as companhias estaduais.

Como os recursos financeiros obtidos pelas companhias, como regra, eram utilizados conforme as prioridades e estratégias de gestão da própria prestadora, foi estabelecida uma relação delicada entre estados e municípios. Afinal, o acesso aos serviços de saneamento deveria ser submetido às políticas dos estados (SOUSA, 2011). Esse mecanismo de poder político e financeiro dos estados pode explicar o porquê de essas companhias serem atualmente o modelo de prestação de serviços de abastecimento de água majoritário no país. Alguns trabalhos acadêmicos no Brasil, que envolvem a avaliação das diferentes modalidades de prestação de serviços de saneamento, apesar de recentes, evidenciaram que os variados modelos de gestão da prestação dos serviços de saneamento levaram a distintos desempenhos (OGERA; PHILIPPI JR, 2005; HELLER et al., 2006; REZENDE et al., 2007; HELLER et al., 2009; LOUREIRO, 2009; HELLER et al., 2012). 
Ao estudar a gestão de água e esgoto nos municípios de Campinas (gestão indireta por meio de empresa de economia mista de capital aberto), Santo André (autarquia municipal) e São José dos Campos e Santos (companhias estaduais), Ogera e Philippi Jr (2005) confrontaram os instrumentos de políticas públicas (Constituição Federal, Política Nacional de Meio Ambiente, Política Nacional de Recursos Hídricos, entre outros) com os resultados das políticas dos governos de cada município selecionado, verificando que todos os instrumentos avaliados faziam menção de forma direta ou indireta ao saneamento, cabendo, aos gestores, as articulações e integrações por meio de planos, programas e projetos, de forma a transformá-los em políticas públicas locais, integradas ao planejamento da cidade.

No trabalho realizado por Heller et al. (2006), tendo o objetivo de comparar diferentes categorias de gestores de serviços de saneamento básico encontrados em Minas Gerais, adotando como referência os anos de 1989 e 1998, foram obtidos como principais resultados: i) a existência de diferenças na forma de prestação dos serviços em relação aos tipos de gestor; ii) o bom desempenho da companhia estadual em aspectos operacionais; iii) o destaque das autarquias municipais quanto aos maiores valores de cobertura por rede de água.

Por outro lado, Rezende et al. (2007) avaliaram os determinantes da presença de serviços de abastecimento de água e esgotamento sanitário nos domicílios urbanos brasileiros, verificando que, entre os modelos de prestação dos serviços, as maiores chances de presença de redes domiciliares de água e esgotamento pertencem aos municípios da região Sudeste e com gestão do tipo autarquia.

Heller et al. (2009), ao realizar a avaliação comparativa na dimensão tecnológica para os serviços de abastecimento de água e esgotamento sanitário de quatro municípios integrantes da bacia do rio das Velhas em Minas Gerais, constataram que o serviço administrado diretamente por prefeitura municipal apresentou o pior desempenho tecnológico, apesar dos altos valores de cobertura por rede de água e de esgotos. Os autores mostraram, ainda, que os serviços disponibilizados pela companhia regional se destacaram pelo alto desempenho tecnológico empregado na operação dos serviços e pelos maiores valores de tarifas adotados.

Em trabalho conduzido por Loureiro (2009), foram comparados diferentes modelos de gestão de serviços de saneamento no estado da Bahia. A pesquisadora destacou a pequena quantidade de municípios titulares dos serviços com um planejamento estruturado, ficando essa função a cargo do próprio prestador.

Em outro estudo, Heller et al. (2012) avaliaram comparativamente as principais modalidades de prestação de serviços públicos de abastecimento de água no conjunto dos municípios brasileiros, por meio de indicadores de desempenho referentes aos aspectos operacionais e gerenciais dos serviços. Os resultados apontaram diferenças significativas entre os modelos avaliados. Nesse trabalho, destacaram-se positivamente os modelos regionais e empresas privadas no tocante a aspectos financeiros - maior índice de hidrometração e menor inadimplência -; por outro lado, os serviços de administração indireta se sobressaíram por números inferiores de reclamações sobre o valor cobrado pelos serviços.

Partindo da premissa de que as políticas públicas e a gestão dos serviços de saneamento devem ser formuladas e avaliadas considerando os modelos de organização do estado - marcos legais, políticos e institucionais - para sua provisão universal, visando a consolidá-lo como um direito social dos cidadãos, busca-se, neste trabalho, compreender, com base em características municipais e de desempenho do prestador, quais são os condicio- 
nantes que influenciam a presença de determinado modelo de gestão no abastecimento de água no Brasil.

\section{MATERIAL E MÉTODOS}

A fim de operar com as informações sobre os serviços de abastecimento de água dos municípios brasileiros e os dados populacionais, foram utilizados, neste trabalho, microdados obtidos a partir da PNSB e do Censo Demográfico, realizados pelo Instituto Brasileiro de Geografia e Estatística (IBGE), referentes aos anos de 2008 e 2010, respectivamente.

Já os microdados referentes aos aspectos econômicos e sociais dos municípios brasileiros foram obtidos por meio do Atlas do Desenvolvimento Humano no Brasil 2013, elaborado pelo Programa das Nações Unidas para o Desenvolvimento (PNUD), pelo Instituto de Pesquisa Econômica Aplicada (IPEA) e pela Fundação João Pinheiro (FJP).

O número de informantes da PNSB foi definido, pelo IBGE, como sendo o número de unidades prestadoras de serviços de saneamento básico, públicas ou privadas, em cada município brasileiro. Assim, um município com serviços de abastecimento de água, esgotamento sanitário, manejo de resíduos sólidos e manejo de águas pluviais poderá ter vários informantes para a PNSB. Vale destacar que a PNSB 2008 apresenta desagregações espaciais de acordo com cada modelo de questionário aplicado. Assim, para os blocos de informações do questionário sobre abastecimento de água e esgotamento sanitário, a desagregação espacial ocorreu até o nível distrital.

Por essa razão, o primeiro contato do IBGE com o município foi a prefeitura municipal; a partir desse contato, foi identificado o número de informantes, conforme consta no questionário “Gestão Municipal do Saneamento Básico". Para tal, foram consideradas entidades prestadoras dos serviços de saneamento apenas aquelas que possuem registro no Cadastro Nacional da Pessoa Jurídica (CNPJ), do Ministério da Fazenda.

Nesse sentido, considerando o total de municípios brasileiros, foram identificadas 11.128 entidades prestadoras dos serviços de abastecimento de água. Cabe destacar que um mesmo município pode apresentar mais de um tipo de constituição jurídica dessas entidades.

Como pressuposto principal para a montagem do banco de dados referente à natureza jurídica do modelo de prestação dos serviços extraídos da PNSB, estabeleceu-se que a entidade mais representativa da gestão do abastecimento de água no município é aquela que atende ao maior número de economias abastecidas na sede municipal. Dessa forma, foi considerado na montagem do banco de dados apenas o principal prestador do serviço, ou seja, uma entidade por município. Nesse sentido, a unidade municipal foi denominada, no presente estudo, "distrito-sede".

A compatibilização dos dados extraídos da PNSB com os demais bancos de dados (Censo Demográfico e Atlas do Desenvolvimento Humano no Brasil 2013) foi realizada por meio de planilha eletrônica, utilizando como filtro o ordenamento crescente, sendo empregado como critério o código utilizado pelo IBGE para identificação dos municípios. A partir do primeiro filtro, os dados foram classificados e ordenados em relação ao nome do município e, em seguida, realizou-se a conferência uma a uma das variáveis do novo banco de dados utilizado no trabalho, obtido a partir das três fontes de informação.

Por falta de compatibilidade no código identificador e no nome do município, foram excluídos 35 municípios. Além disso, em função da inexpressiva participação na oferta efetiva do abastecimento de água e esgotamento sanitário, optou-se por excluir da análise os municípios que informaram que os serviços são prestados por associações (25), consórcios (dez) e fundações (dois). Foi, então, excluído 
um total de 72 "distritos-sede" das análises do presente trabalho, o que corresponde a $1,30 \%$ do universo amostral. Diante disso, foram levantadas informações dos serviços de abastecimento de água de 5.493 casos ("distritos-sede"), atingindo a quase totalidade dos municípios brasileiros - 98,70\% dos 5.565 municípios (IBGE, 2010).

Na Tabela 1, consta a descrição do agrupamento da natureza jurídica, do número de casos e das siglas adotadas na sistematização dos dados.

Diante do que foi relatado, buscou-se analisar e entender os modelos adotados para prestação de serviços de abastecimento de água em função das características dos municípios relativas às seguintes dimensões: i) geográfica e populacional; ii) econômica; iii) desenvolvimento humano; e iv) desempenho do prestador.

$\mathrm{Na}$ construção dos indicadores e na seleção das variáveis adotadas no trabalho, foram obedecidas as categorias apontadas na fase de revisão da literatura e nos estudos conduzidos por Sanchez (2001), Costa (2003), Rezende (2005), Bessa (2006), Toneto e Saiani (2006), Rezende et al. (2007), Souza (2011), IBGE (2012), Heller (2012) e PNUD, IPEA e FJP (2013).

Entre as variáveis selecionadas no trabalho, todas possuem como abrangência a área urbana da sede municipal, exceto para as variáveis taxa de urbanização, índice de Gini e Índice de Desenvolvimento Humano Municipal (IDH-M), que possuem como alcance o município.

Tabela 1 - Descrição do agrupamento das naturezas jurídicas, do número de casos e das siglas adotadas na sistematização dos dados para as prestadoras de serviço de abastecimento de água.

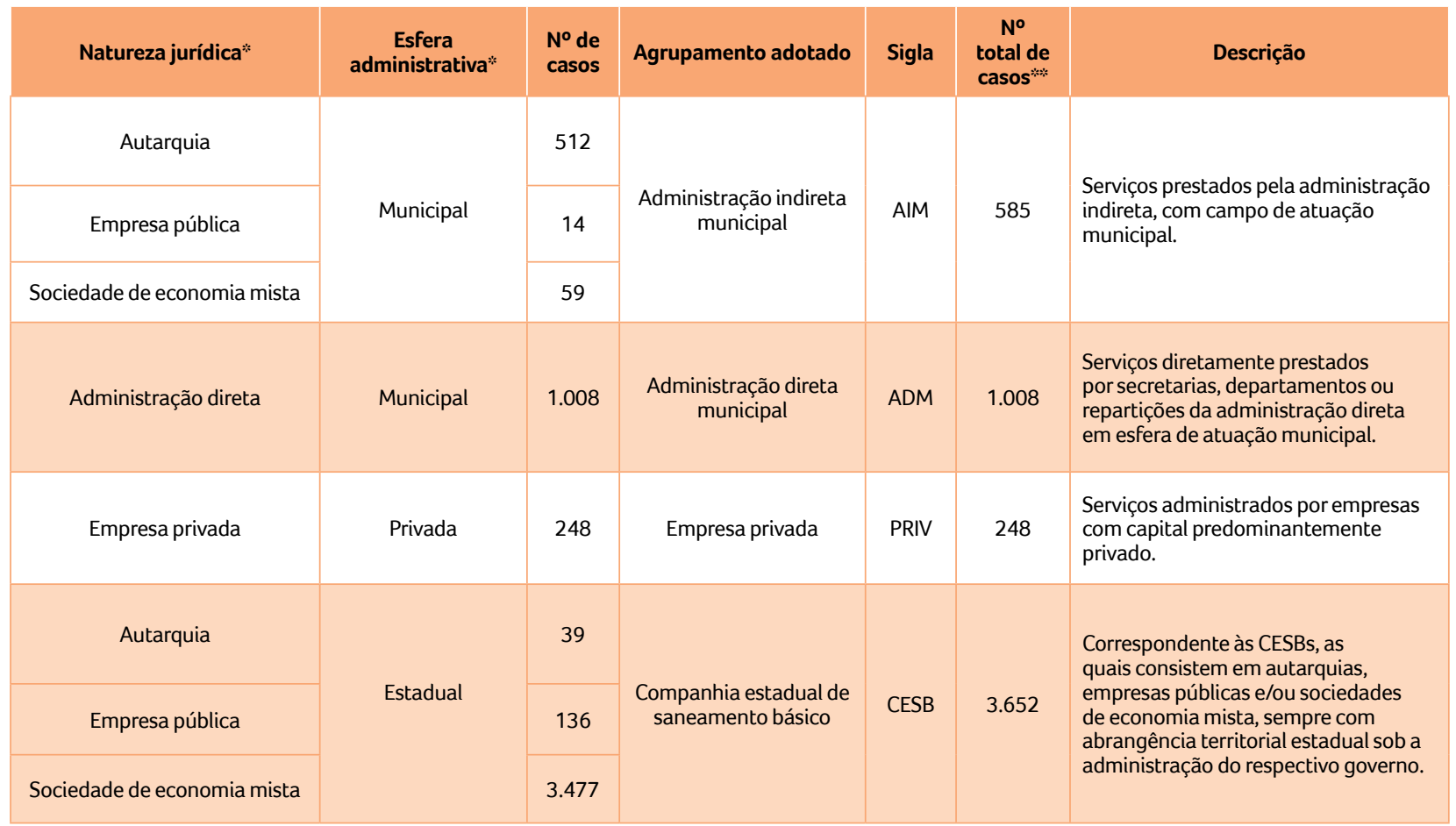

Notas: * Denominação mantida conforme a PNSB 2008. * Corresponde à quantidade de distritos-sede, totalizando 5.493 casos. 
Na Tabela 2, é apresentada uma descrição dos critérios adotados, bem como as fontes dos dados das variáveis explicativas que foram utilizadas nos testes estatísticos univariados e no modelo estatístico multivariado.

Após a realização de todas as análises preliminares de consistência dos dados, procedeu-se à seleção das variáveis de interesse para o estudo. Foram realizadas análises de frequência, por meio de estatísticas descritivas básicas, visando ao conhecimento do comportamento das variáveis e da qualidade de seus dados. A partir da montagem e da sistematização do banco de dados, foram avaliadas as observações atípicas, faltantes ou infrequentes - denominadas outliers ou missing -, de acordo com a natureza de cada indicador. Em alguns casos, estas foram excluídas da amostra de dados.

As variáveis obtidas foram inicialmente testadas quanto à normalidade, homogeneidade e aderência das variâncias, utilizando os testes Shapiro-Wilk e Qui-quadrado, disponíveis no software Statsoft Statistica ${ }^{\circledR}$ (STATSOFT, 2007). Diante da verificação de que a distribuição normal não se aplicou às amostras de dados, fato já esperado conforme estudos encontrados na literatura especializada (OLIVEIRA, 2006; REZENDE, 2008; HELLER, 2012), recorreu-se a um escopo de métodos inferenciais compostos por testes não paramétricos.

As variáveis independentes contínuas (Tabela 2) foram avaliadas segundo análise de variância de medianas por meio do teste Kruskal-Wallis e, quando detectadas diferenças significativas entre as amostras independentes, aplicou-se o teste de comparações múltiplas - teste z proposto por Siegel e Castellan (1988)-, ao nível de 5\% de probabilidade, disponível no programa Statsoft Statistica ${ }^{\circledR}$.

Para auxílio em apresentação, interpretação e discussão dos dados, foram utilizados gráficos box-plot e inferências da distribuição dos valores das variáveis em termos de medida de posição.

Tabela 2 - Quadro-resumo dos critérios adotados e fontes dos dados na elaboração das variáveis-resposta do modelo estatístico.

\begin{tabular}{|c|c|c|c|c|c|}
\hline \multicolumn{2}{|c|}{ Variáveis dependentes } & \multicolumn{4}{|c|}{ Variáveis independentes } \\
\hline \multicolumn{2}{|c|}{ Características dos modelos de prestação } & \multicolumn{4}{|c|}{ Características dos municípios } \\
\hline $\begin{array}{c}\text { Agrupamento (natureza } \\
\text { jurídica) }\end{array}$ & Fonte de dados & Indicador & Variáveis & Unidade & Fonte de dados \\
\hline $\begin{array}{l}\text { Administração Direta } \\
\text { Municipal (ADM) }\end{array}$ & \multirow{4}{*}{$\begin{array}{l}\text { Pesquisa Nacional de } \\
\text { Saneamento Básico } \\
\text { (PNSB, 2010) }\end{array}$} & $\begin{array}{l}\text { Geográfico e } \\
\text { populacional }\end{array}$ & $\begin{array}{c}\text { Macrorregiões } \\
\text { População da area urbana } \\
\text { da sede } \\
\text { Densidade populacional } \\
\text { urbana da sede } \\
\text { Taxa de urbanização }\end{array}$ & $\begin{array}{c}\mathrm{N}, \mathrm{NE}, \mathrm{SE}, \mathrm{S}, \mathrm{CO} \\
\text { habitantes } \\
\text { habitantes } / \mathrm{km}^{2} \\
\%\end{array}$ & $\begin{array}{l}\text { Censo Demográficc } \\
\text { (IBGE, 2013) }\end{array}$ \\
\hline $\begin{array}{l}\text { Administração Indireta } \\
\text { Municipal (AIM) }\end{array}$ & & Econômico & $\begin{array}{c}\text { Renda domiciliar per capita } \\
\text { Índice de Gini }^{(1)} \\
\text { Proporção dos } \\
\text { Extremamente pobres } \\
\text { (2) }\end{array}$ & $\begin{array}{c}\mathrm{R} \$ \\
- \\
\%\end{array}$ & \multirow{3}{*}{$\begin{array}{c}\text { Atlas do } \\
\text { Desenvolvimento } \\
\text { Humano no Brasil } \\
\text { (PNUD; IPEA; FJP, } \\
\text { 2013) } \\
\text { Pesquisa Nacional } \\
\text { de Saneamento } \\
\text { Básico } \\
\text { (PNSB, 2010) }\end{array}$} \\
\hline $\begin{array}{l}\text { Companhia Estadual de } \\
\text { Saneamento Básico (CESB) }\end{array}$ & & $\begin{array}{c}\text { Desenvolvimento } \\
\text { humano }\end{array}$ & $\mathrm{IDH}-\mathrm{M}^{(3)}$ & - & \\
\hline Empresa Privada (PRIV) & & $\begin{array}{l}\text { Desempenho do } \\
\text { prestador }\end{array}$ & $\begin{array}{c}\text { Inadimplência }{ }^{(4)} \\
\text { Índice de perda de } \\
\text { faturamento }^{(5)} \\
\text { Economias abastecidas }^{(6)}\end{array}$ & $\begin{array}{l}\% \\
\text { quantidade de } \\
\text { instalações }\end{array}$ & \\
\hline
\end{tabular}

Notas: (1) Mede o grau de desigualdade existente na distribuição de indivíduos segundo a renda domiciliar per capita. Seu valor varia de 0 , quando não há desigualdade (a renda domiciliar per capita de todos os indivíduos tem o mesmo valor), a 1, quando a desigualdade é máxima (apenas um indivíduo detém toda a renda). (2) Proporção dos indivíduos com renda domiciliar per capita igual ou inferior a R\$70,00 mensais, em valores de agosto de 2010. (3) Representa a média geométrica dos índices das dimensões renda, educação e longevidade, com pesos iguais. (4) Percentual médio de inadimplência nos últimos 12 meses. (5) Índice médio de perdas de faturamento da água (IPF) apurado nos últimos 12 meses. (6) Número total de economias abastecidas, incluindo consumo residencial, comercial, industrial, público e outras. 
Em relação à análise quantitativa do indicador categórico (variável macrorregião), foi utilizada a ferramenta estatística do teste Qui-quadrado, seguida da análise multivariada denominada análise de correspondência.

Tendo em vista as diferenças acentuadas das amostras para cada natureza jurídica, conforme Tabela 1, foi verificado o efeito dessas amostras diferentes, aplicando-se alguns dos testes estatísticos, simulando amostras com tamanhos homogêneos ( $n=248)$, a partir de uma seleção aleatória realizada pelo software estatístico Statsoft Statistica ${ }^{\circledR}$. Os resultados dos testes foram semelhantes aos valores apresentados pela amostra total, indicando que a diferença de tamanho entre os grupos possivelmente não influenciou os resultados estatísticos apresentados.

\section{RESULTADOS E DISCUSSÃO}

A natureza jurídica das entidades prestadoras dos serviços de abastecimento de água no Brasil e a proporção de sua participação no total de distritos-sede brasileiros em função das macrorregiões estão apresentadas na Tabela 3.
Destaca-se a significativa participação das CESBs, que representam mais da metade do total de sistemas de abastecimento de água nas macrorregiões brasileiras, exceto na região Norte.

Esse panorama é um reflexo da política implementada durante as duas primeiras décadas (1970/80) do PLANASA, praticado durante o governo militar, o qual condicionava os investimentos em saneamento à transferência dos serviços, por meio de concessões aos estados, tendo um contingente elevado de municípios cedido a essa exigência. É importante salientar que os investimentos não priorizaram municípios com porte populacional pequeno, sendo preferencialmente direcionados àqueles com mais de 50 mil habitantes. Entretanto, alguns desses municípios, especialmente aqueles cujos serviços estavam sob a gestão de autarquias durante a vigência do PLANASA, não transferiram a prestação dos serviços de saneamento às companhias estaduais.

Por outro lado, a participação do investimento privado, que, no Brasil, representa 4,51\% do total de distritos-sede (Tabela 3), é problematizada por Hall e Lobina (2009), que a consideram historica-

Tabela 3 - Natureza jurídica dos prestadores de serviços de abastecimento de água em relação às macrorregiões brasileiras (análise estatística realizada na linha).

\begin{tabular}{|c|c|c|c|c|c|c|c|}
\hline \multirow{2}{*}{\multicolumn{2}{|c|}{ Macrorregião }} & \multicolumn{4}{|c|}{ Agrupamento natureza jurídica } & \multirow{2}{*}{ Total por macrorregião } & \multirow{2}{*}{ Valor-p } \\
\hline & & ADM & AIM & CESB & PRI & & \\
\hline \multirow{2}{*}{ Norte } & $\mathbf{n}^{*}$ & 118 & 47 & 139 & 138 & 442 & \multirow{10}{*}{0,000} \\
\hline & $\%$ & 26,70 & 10,63 & 31,45 & 31,22 & 100 & \\
\hline \multirow{2}{*}{ Nordeste } & $\mathbf{n}^{*}$ & 222 & 175 & 1.352 & 13 & 1.762 & \\
\hline & $\%$ & 12,60 & 9,93 & 76,73 & 0,74 & 100 & \\
\hline \multirow[b]{2}{*}{ Sudeste } & $\mathbf{n}^{*}$ & 351 & 227 & 1.056 & 31 & 1.665 & \\
\hline & $\%$ & 21,08 & 13,63 & 63,43 & 1,86 & 100 & \\
\hline \multirow{2}{*}{ Sul } & $\mathbf{n}^{*}$ & 184 & 103 & 815 & 27 & 1.129 & \\
\hline & $\%$ & 16,30 & 9,12 & 72,19 & 2,39 & 100 & \\
\hline \multirow{2}{*}{ Centro-Oeste } & $\mathbf{n}^{*}$ & 133 & 33 & 290 & 39 & 495 & \\
\hline & $\%$ & 26,87 & 6,67 & 58,58 & 7,88 & 100 & \\
\hline
\end{tabular}

Notas: $\mathrm{n}^{*}$ : número de casos ou distritos-sede. \%: porcentagem em relação ao total. Valor-p ${ }^{* * *}$ : significativo calculado pelo teste Qui-quadrado. 
mente pouco relevante em termos de desempenho e pertinência nos países em desenvolvimento.

Os resultados das análises estatísticas da variável categórica macrorregiões brasileiras (Tabelas 3 e 4) são provenientes de análises realizadas em linha e em coluna, ou seja, dentro de cada uma das cinco macrorregiões em relação à distribuição das quatro naturezas jurídicas no Brasil. Conforme evidenciado, existem associações significativas (valor- $p=0,000$ ) entre as macrorregiões e as naturezas jurídicas.

Na Figura 1, estão representadas as categorias de naturezas jurídicas e macrorregiões brasileiras no plano bidimensional, utilizando a técnica multivariada de análise de correspondência. Percebe-se que existe contraste na distribuição das naturezas jurídicas dos prestadores de serviços de abastecimento de água em relação às macrorregiões brasileiras. Nesse sentido, nota-se que as PRIV estão fortemente associadas à região Norte.

Por outro lado, verifica-se homogeneidade entre as CESBs nas regiões Nordeste e Sul. Também se percebe relação entre AIM e a região Sudeste e entre ADM e a região Centro-Oeste. 0 mapa perceptual gerado por meio da análise de correspondência permite visualizar essas associações (Figura 1).

As Tabelas 3 e 4 e a Figura 1 chamam atenção para a maior proporção de atuação das PRIV na provisão dos sistemas de abastecimento de água (55,65\% em relação ao total no Brasil) nos estados localizados na região Norte $(31,22 \%$ na macrorregião). Isso pode indicar um fator regional nas organizações e provisão dos serviços de saneamento. Cabe destacar que, quando realizadas análises específicas dos dados, se verifica que 47 distritos-sede operados por PRIV estão localizados no estado de Tocantins. Esses municípios somam cerca de $80 \%$ da população do estado.

Com sede em Palmas, a Companhia de Saneamento do Tocantins (FOZ/SANEATINS), desde 1998, é uma empresa de economia mista, envolvendo parcerias do governo do estado do Tocantins e prefeituras municipais, e com gestão privada exercida pela empresa Foz Centro Norte S.A. (FCN). Nesse sentido, com base no conjunto total de dados, a participação da FOZ/SANEATINS corresponde a $18,95 \%$ e $34,05 \%$ de PRIV do Brasil e da região Norte, respectivamente.

Tabela 4 - Natureza jurídica dos prestadores de serviços de abastecimento de água em relação às macrorregiões brasileiras (análise estatística realizada na coluna).

\begin{tabular}{|c|c|c|c|c|c|c|c|c|c|}
\hline \multirow{3}{*}{ Macrorregião } & \multicolumn{8}{|c|}{ Agrupamento natureza jurídica } & \multirow{3}{*}{ Valor-p } \\
\hline & \multicolumn{2}{|c|}{ ADM } & \multicolumn{2}{|c|}{ AIM } & \multicolumn{2}{|c|}{ CESB } & \multicolumn{2}{|c|}{ PRIV } & \\
\hline & $\mathbf{n}^{*}$ & $\%$ & $\mathbf{n}^{*}$ & $\%$ & $\mathbf{n}^{*}$ & $\%$ & $n^{*}$ & $\%$ & \\
\hline Norte & 118 & 11,71 & 47 & 8,03 & 139 & 3,81 & 138 & 55,65 & \multirow{6}{*}{0,000} \\
\hline Nordeste & 222 & 22,02 & 175 & 29,91 & 1.352 & 37,02 & 13 & 5,24 & \\
\hline Sudeste & 351 & 34,82 & 227 & 38,80 & 1.056 & 28,92 & 31 & 12,50 & \\
\hline Sul & 184 & 18,25 & 103 & 17,61 & 815 & 22,32 & 27 & 10,89 & \\
\hline Centro-Oeste & 133 & 13,19 & 33 & 5,64 & 290 & 7,94 & 39 & 15,73 & \\
\hline Total no Brasil & 1.008 & 100 & 585 & 100 & 3.652 & 100,00 & 248 & 100,00 & \\
\hline
\end{tabular}

Notas: $n^{*}$ : número de casos ou distritos-sede. \%: porcentagem em relação ao total. Valor-p***: significativo calculado pelo teste Qui-quadrado. 


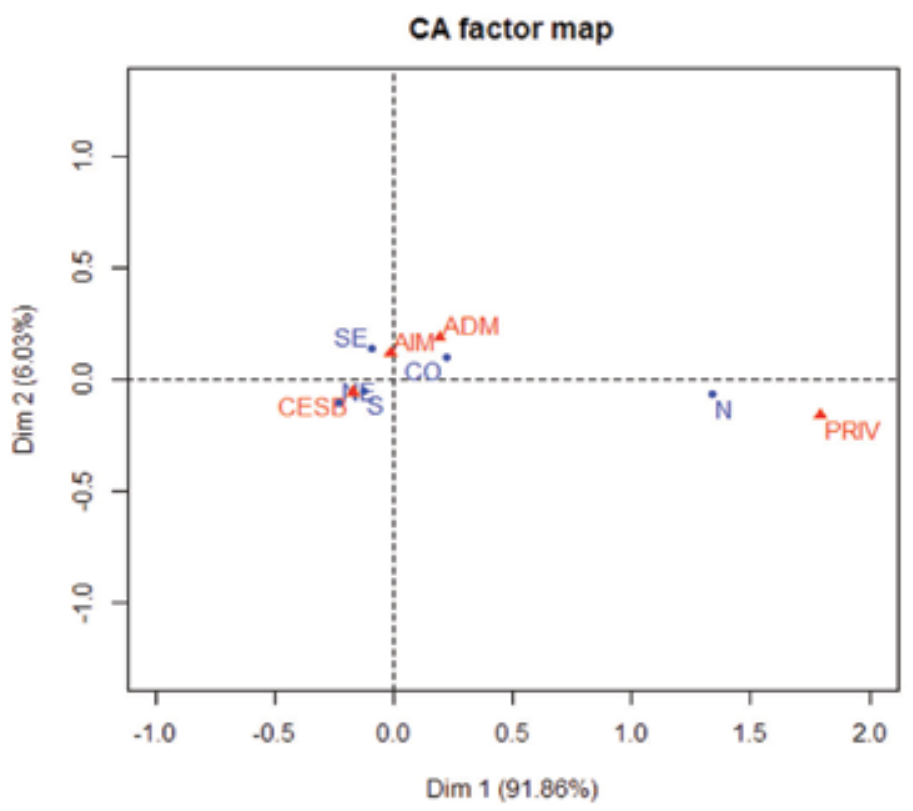

Figura 1 - Mapa perceptual gerado por meio da análise de correspondência, associando as naturezas jurídicas e as macrorregiões brasileiras.

Quando analisada a natureza jurídica em função da população urbana do distrito-sede (Figura 5), percebe-se uma maior participação das autarquias, seguidas das CESBs e PRIV, onde as populações são mais numerosas. Isso pode indicar maior predominância de ações desses tipos de prestador em locais onde há maior quantidade de potenciais consumidores dos serviços.

O que pode corroborar essa constatação é o fato de existirem apenas dez municípios - todas capitais de estado - com mais de um milhão de habitantes no distrito-sede, o que representa aproximadamente $0,2 \%$ do total dos municípios brasileiros. Destes, oito têm sistemas de abastecimento de água operados por CESB (São Paulo, Rio de Janeiro, Salvador, Brasília, Curitiba, Recife, Belo Horizonte, Goiânia), um, por AIM (Porto Alegre) e outro, por PRIV (Manaus).
No outro extremo, pela análise dos 100 municípios que possuem a menor quantidade de habitantes nos distritos-sede brasileiros, constata-se que 71 possuem serviço de abastecimento de água prestado por ADM, 24, por CESB, quatro, por PRIV e apenas um município é atendido por AIM. Essa constatação pode ser explicada pelo fato de os municípios de menor porte populacional possuírem dificuldades no acesso ao financiamento para a provisão dos serviços de saneamento, sendo os sistemas assumidos pelos próprios titulares - os municípios.

As CESBs atendem a $68,96 \%$ da população urbana da sede em abastecimento de água. Uma das justificativas para a adoção desse modelo, quando de sua implantação nos anos 1970, foi que a gestão regional dos serviços de saneamento possibilitaria aos municípios menores e de baixa renda o acesso à água e ao esgotamento sanitário com 


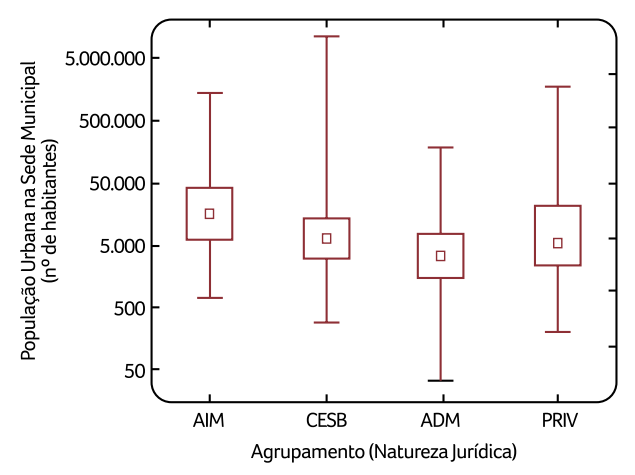

\begin{tabular}{|c|c|c|c|c|c|c|}
\hline \multirow{2}{*}{\multicolumn{2}{|c|}{$\begin{array}{l}\text { Natureza } \\
\text { jurídica" }\end{array}$}} & \multicolumn{5}{|c|}{$\begin{array}{l}\text { População urbana da sede } \\
\text { (nº habitantes) * }\end{array}$} \\
\hline & & \multirow{2}{*}{$\begin{array}{c}\text { Md } \\
15.391\end{array}$} & \multirow{2}{*}{$\begin{array}{c}\mathbf{1}^{\circ} \mathbf{Q}_{(1 / 4)} \\
6.210\end{array}$} & \multirow{2}{*}{$\begin{array}{l}3^{\circ} \mathbf{Q}_{(3 / 4)} \\
42.630\end{array}$} & \multirow{2}{*}{$\begin{array}{c}X \\
48.398\end{array}$} & \multirow{2}{*}{$\begin{array}{c}\text { D.P. } \\
109,19\end{array}$} \\
\hline AIM & $\mathbf{a}$ & & & & & \\
\hline CESB & b & 5.922 & 2.320 & 21.420 & 27.032 & 232,00 \\
\hline PRIV & b & 5.256 & 2.950 & 13.480 & 34.640 & 133,24 \\
\hline ADM & c & 3.107 & 1.430 & 7.850 & 7.503 & 14,68 \\
\hline
\end{tabular}

Quadro-resumo: *Significativo para o teste não paramétrico Kruskal-Wallis (valor-p = 0,000). \#Naturezas jurídicas seguidas pela mesma letra não diferem estatisticamente $(\alpha=0,05)$ pelo teste de comparações múltiplas.

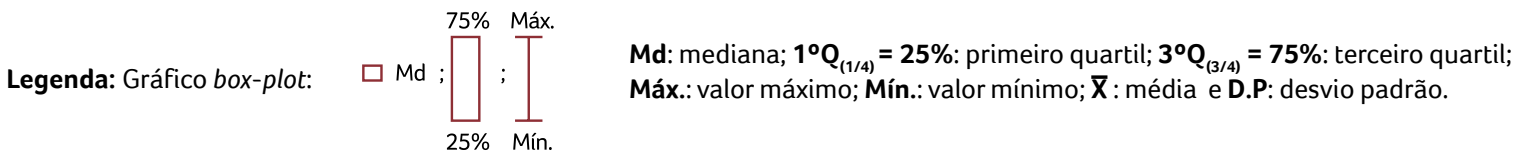

Figura 5 - Gráfico box-plot e quadro-resumo dos testes estatísticos não paramétricos da natureza jurídica em função da população urbana do distrito-sede.

melhor qualidade, a preços módicos, por meio da economia de escala e do subsídio cruzado.

Já as AIMs e ADMs são responsáveis pela provisão de água em $19,77 \%$ e 5,28\% da população urbana da sede, respectivamente.

Aproximadamente 8,5 milhões de pessoas são atendidas por sistemas de abastecimento de água operados pelo setor privado, um montante que equivale a $6 \%$ da população urbana das sedes municipais, estando presente em 248 distritos-sede e em 20 de um total de 27 unidades federativas brasileiras. Ao realizar uma projeção sobre a intenção desses operadores nos próximos anos, a Associação Brasileira das Concessionárias Privadas dos Serviços Públicos de Água e Esgoto (ABCON, 2014) ressalta que o interesse das empresas é ampliar o atendimento para $30 \%$ da população urbana brasileira.

Ao analisar as tentativas de privatização de sistemas municipais de saneamento básico no estado de São Paulo, Sanchez (2001) constatou que, dos 54 municípios do estado com sistemas municipais e mais de 50 mil habitantes, 47 apresentavam índice de cobertura de abastecimento de água superior a $90 \%$ e, em 43 deles, a cobertura de esgotos canalizados era de aproximadamente $75 \%$.

Estudo conduzido por Souza (2011) verificou que o percentual de oferta dos serviços de saneamento é maior nos municípios com mais de 200 mil habitantes, sendo observado o crescimento com o aumento do porte municipal. Nesses, fica evidente a situação desfavorável do esgotamento sanitário em relação ao abastecimento de água, visto que os municípios com mais de 200 mil habitantes apresentam cerca de $92,00 \%$ de cobertura de rede de água e $69,50 \%$ de rede de esgoto. Entretanto, é preciso destacar que, nos municípios pequenos, as soluções individuais são comumente utilizadas, podendo ser adequadas no contexto em que se inserem. Nesse sentido, é bom ressalvar que essa baixa cobertura nem sempre implica uma situação desfavorável.

Como pode ser verificado na Figura 6, a distribuição das naturezas jurídicas dos diversos modelos 
de prestação dos serviços de abastecimento de água apresenta diferenças estatisticamente significativas em função da densidade demográfica dos distritos-sede brasileiros. Nesse sentido, cada natureza jurídica foi significativamente diferente das demais, sendo que AIM apresentou a maior mediana, seguida de CESB, ADM e PRIV.

Cabe destacar que a densidade demográfica constitui um referencial importante para avaliação da distribuição da terra urbana, de infraestrutura e serviços públicos e, consequentemente, dos impactos no meio natural e na qualidade de vida. No caso dos sistemas de abastecimento de água, devido às suas características peculiares de monopólio natural, fatores como abrangência e número de potenciais usuários são importantes para o ganho de economia de escala.

$\mathrm{Na}$ Figura 7, são apresentados os resultados da natureza jurídica do distrito-sede em função da taxa de urbanização do município. Como pode ser verificado, o grupo formado pelas naturezas jurí- dicas AIM e PRIV, seguidas das CESBs, está associado aos municípios que possuem maiores taxas de urbanização. Por outro lado, a ADM está relacionada aos municípios que apresentam menores taxas de urbanização.

$\mathrm{Na}$ Figura 8, pode-se verificar que a renda per capita foi significativamente diferente entre as naturezas jurídicas, sendo que AIM apresentou mediana significativamente maior que as demais naturezas, entre as quais não foram encontradas diferenças significativas.

Quando analisada a variável índice de Gini (Figura 9), percebe-se diferença significativa entre as naturezas jurídicas, sendo que ADM apresentou mediana significativamente menor que as demais naturezas. Já a proporção dos extremamente pobres (Figura 10) apresentou diferenças significativas entre as naturezas jurídicas, sendo que AIM apresentou mediana significativamente menor que as demais naturezas.

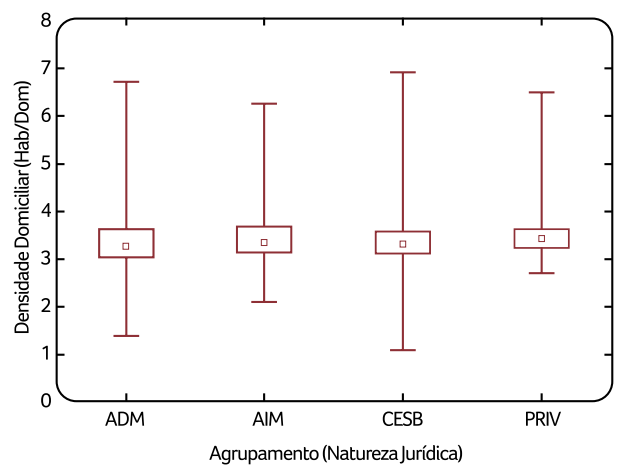

\begin{tabular}{|c|c|c|c|c|c|c|}
\hline \multirow{2}{*}{\multicolumn{2}{|c|}{$\begin{array}{l}\text { Natureza } \\
\text { jurídica" }\end{array}$}} & \multicolumn{5}{|c|}{$\begin{array}{l}\text { Densidade domiciliar urbana } \\
\text { (habitantes/domicílio)* }\end{array}$} \\
\hline & & \multirow{2}{*}{$\begin{array}{l}\text { Md } \\
3,63\end{array}$} & \multirow{2}{*}{$\begin{array}{c}\mathbf{1}^{\circ} \mathbf{Q}_{(1 / 4)} \\
3,24\end{array}$} & \multirow{2}{*}{$\begin{array}{c}3^{\circ} \mathbf{Q}_{(3 / 4)} \\
3,74\end{array}$} & \multirow{2}{*}{$\begin{array}{c}\bar{X} \\
3,80\end{array}$} & \multirow{2}{*}{$\begin{array}{l}\text { D.P. } \\
0,46\end{array}$} \\
\hline PRIV & $\mathbf{a}$ & & & & & \\
\hline AIM & $a$ & 3,43 & 3,12 & 3,67 & 3,46 & 0,49 \\
\hline CESB & b & 3,26 & 3,09 & 3,55 & 3,39 & 0,50 \\
\hline ADM & b & 3,25 & 3,03 & 3,64 & 3,42 & 0,58 \\
\hline
\end{tabular}

Quadro-resumo: "Significativo para o teste não paramétrico Kruskal-Wallis (valor-p $=0,000$ ). "Naturezas jurídicas seguidas pela mesma letra não diferem estatisticamente $(\alpha=0,05)$ pelo teste de comparações múltiplas.

Legenda: Gráfico box-plot: $\square$ Md ; $\prod_{25 \%}^{75 \%} ; \prod_{\text {Min. }}^{\text {Máx. }}$ Md: mediana; $\mathbf{1}^{\circ} \mathrm{Q}_{(1 / 4)}=\mathbf{2 5 \%}$ : primeiro quartil; $3^{\circ} \mathrm{Q}_{(3 / 4)}=\mathbf{7 5 \%}$ : terceiro quartil; Máx.: valor máximo; Mín.: valor mínimo; $\mathbf{X}$ : média e D.P: desvio padrão.

Figura 6 - Gráfico box-plot e quadro-resumo dos testes estatísticos não paramétricos da natureza jurídica em função da densidade domiciliar urbana do município (habitantes/domicílio). 


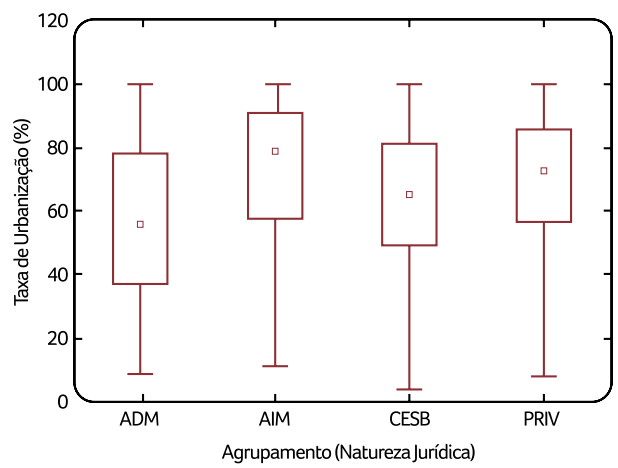

\begin{tabular}{|c|c|c|c|c|c|c|}
\hline \multirow{2}{*}{\multicolumn{2}{|c|}{$\begin{array}{l}\text { Natureza } \\
\text { jurídica" }\end{array}$}} & \multicolumn{5}{|c|}{$\begin{array}{l}\text { Taxa de urbanização } \\
\text { (\%)* }\end{array}$} \\
\hline & & \multirow{2}{*}{$\begin{array}{c}\text { Md } \\
78,45\end{array}$} & \multirow{2}{*}{$\begin{array}{c}1^{\circ} \mathbf{Q}_{(1 / 4)} \\
56,97\end{array}$} & \multirow{2}{*}{$\begin{array}{c}3^{\circ} \mathbf{Q}_{(3 / 4)} \\
91,33\end{array}$} & \multirow{2}{*}{$\begin{array}{c}X \\
82,67\end{array}$} & \multirow{2}{*}{$\begin{array}{l}\text { D.P. } \\
21,46\end{array}$} \\
\hline AIM & a & & & & & \\
\hline PRIV & $a$ & 72,31 & 56,03 & 85,55 & 80,00 & 19,95 \\
\hline CESB & b & 65,00 & 48,50 & 91,19 & 84,24 & 20,92 \\
\hline ADM & c & 55,68 & 36,50 & 78,56 & 76,98 & 23,87 \\
\hline
\end{tabular}

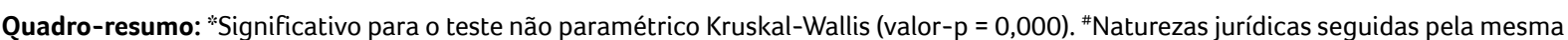
letra não diferem estatisticamente $(\alpha=0,05)$ pelo teste de comparações múltiplas.

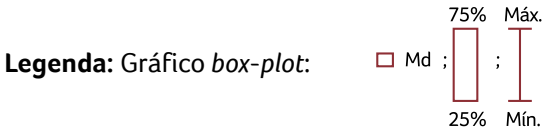

Md: mediana; $\mathbf{1}^{\circ} \mathbf{Q}_{(1 / 4)}=25 \%$ : primeiro quartil; $3^{\circ} \mathbf{Q}_{(3 / 4)}=\mathbf{7 5 \%}$ : terceiro quartil; Máx.: valor máximo; Mín.: valor mínimo; X: média e D.P: desvio padrão.

Figura 7 - Gráfico box-plot e quadro-resumo dos testes estatísticos não paramétricos da natureza jurídica do distrito-sede em função da taxa de urbanização do município (porcentagem da população da área urbana em relação à população total).

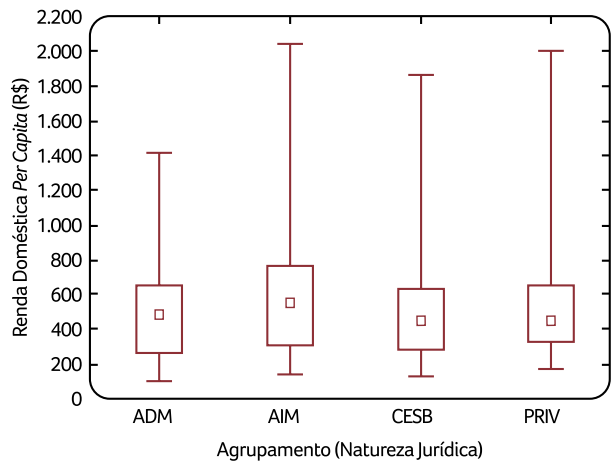

\begin{tabular}{|c|c|c|c|c|c|c|}
\hline \multirow{2}{*}{$\begin{array}{l}\text { Natureza } \\
\text { jurídica" }\end{array}$} & \multicolumn{5}{|c|}{ Renda domiciliar per capita (R\$)** } \\
\cline { 3 - 7 } & & Md & $\mathbf{1}^{\circ} \mathbf{Q}_{(1 / 4)}$ & $3^{\circ} \mathbf{Q}_{(3 / 4)}$ & X & D.P. \\
\hline AIM & a & 543,60 & 301,55 & 761,68 & 564,34 & 287,23 \\
\hline CESB & b & 482,38 & 262,54 & 652,77 & 487,69 & 236,78 \\
\hline PRIV & bc & 451,99 & 278,28 & 632,22 & 482,40 & 233,10 \\
\hline ADM & c & 444,64 & 320,19 & 659,58 & 513,75 & 252,50 \\
\hline
\end{tabular}

Quadro-resumo: "Significativo para o teste não paramétrico Kruskal-Wallis (valor-p =0,000). "Naturezas jurídicas seguidas pela mesma letra não diferem estatisticamente $(\alpha=0,05)$ pelo teste de comparações múltiplas.

Legenda: Gráfico box-plot: $\quad \square$ Md $; \prod_{25 \%}^{75 \%} ; \prod_{\text {Min. }}^{\text {Máx. }} \begin{aligned} & \text { Md: mediana; } \mathbf{1}^{\circ} \mathbf{Q}_{(1 / 4)}=\mathbf{2 5 \%} \text { : primeiro quartil; } \mathbf{3}^{\circ} \mathbf{Q}_{(3 / 4)}=\mathbf{7 5 \%} \text { : terceiro quartil; } \\ & \text { Máx.: valor máximo; } \text { Mín.: valor mínimo; } \mathbf{X}: \text { média e D.P: desvio padrão. }\end{aligned}$

Figura 8 - Gráfico box-plot e quadro-resumo dos testes estatísticos não paramétricos da natureza jurídica em função da renda domiciliar per capita (R\$).

Os resultados indicam que os serviços de abastecimento de água operados diretamente pelo titular (ADM) atuam em municípios que possuem a menor desigualdade social em termos de concen- tração de renda (menor índice de Gini), a segunda maior renda per capita e domicílios com a segunda menor proporção de indivíduos pobres e vulneráveis à pobreza. 


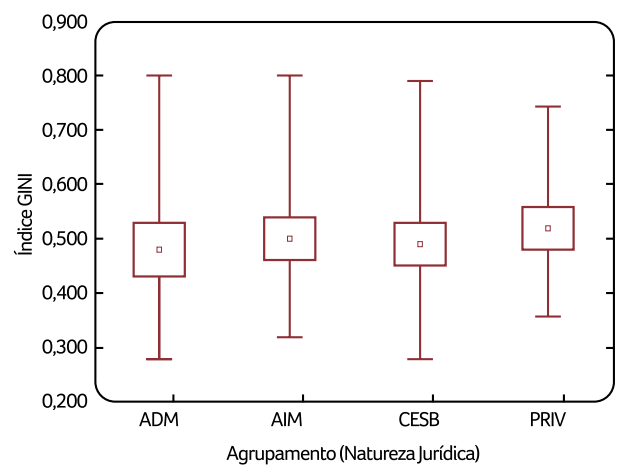

\begin{tabular}{|c|c|c|c|c|c|c|}
\hline \multirow{2}{*}{$\begin{array}{c}\text { Natureza } \\
\text { jurídica" }\end{array}$} & \multicolumn{5}{|c|}{ Índice de GINI * } \\
\cline { 3 - 8 } & Md & $1^{\circ} \mathbf{Q}_{(1 / 4)}$ & $3^{\circ} \mathbf{Q}_{(3 / 4)}$ & X & D.P. \\
\hline PRIV & a & 0,520 & 0,480 & 0,560 & 0,526 & 0,07 \\
\hline AIM & b & 0,500 & 0,460 & 0,540 & 0,501 & 0,06 \\
\hline CESB & c & 0,490 & 0,450 & 0,530 & 0,494 & 0,06 \\
\hline ADM & d & 0,480 & 0,430 & 0,530 & 0,484 & 0,08 \\
\hline
\end{tabular}

Quadro-resumo: "Significativo para o teste não paramétrico Kruskal-Wallis (valor-p =0,000). "Naturezas jurídicas seguidas pela mesma letra não diferem estatisticamente $(\alpha=0,05)$ pelo teste de comparações múltiplas.

Legenda: Gráfico box-plot: $\quad \square$ Md ; $\prod_{25 \%}^{75 \%} ; \prod_{\text {Mín. }}^{\text {Máx. }} \begin{aligned} & \text { Md: mediana; } \mathbf{1}^{\circ} \mathbf{Q}_{(1 / 4)}=\mathbf{2 5 \%} \text { : primeiro quartil; } \mathbf{3}^{\circ} \mathbf{Q}_{(3 / 4)}=\mathbf{7 5 \%} \text { : terceiro quartil; } \\ & \text { Máx.: valor máximo; Mín.: valor mínimo; } \mathbf{X}: \text { média e D.P: desvio padrão. }\end{aligned}$

Figura 9 - Gráfico box-plot e quadro-resumo dos testes estatísticos não paramétricos da natureza jurídica em função do índice de Gini.

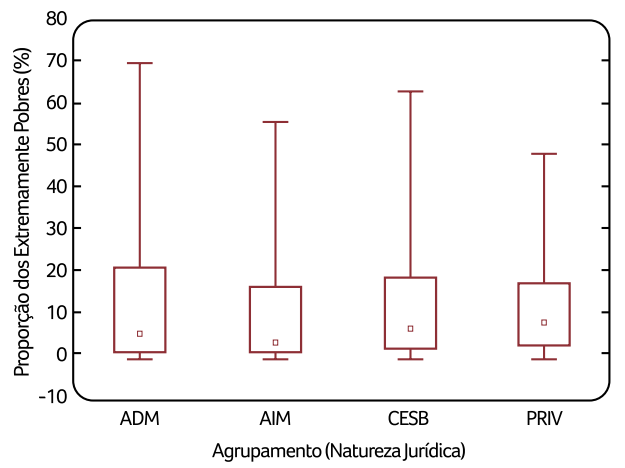

\begin{tabular}{|c|c|c|c|c|c|c|}
\hline \multirow{2}{*}{$\begin{array}{c}\text { Natureza } \\
\text { jurídica" }\end{array}$} & \multicolumn{5}{|c|}{ Proporção dos extremamente pobres* } \\
\cline { 3 - 8 } & & Md & $\mathbf{1}^{\circ} \mathbf{Q}_{(1 / 4)}$ & $\mathbf{3}^{\circ} \mathbf{Q}_{(3 / 4)}$ & $\mathbf{X}$ & D.P. \\
\hline PRIV & a & 8,20 & 2,72 & 17,17 & 11,20 & 10,31 \\
\hline CESB & ab & 6,75 & 1,88 & 18,95 & 11,29 & 11,26 \\
\hline ADM & b & 5,76 & 1,31 & 21,38 & 12,24 & 13,61 \\
\hline AIM & c & 3,80 & 1,05 & 16,55 & 9,77 & 11,52 \\
\hline
\end{tabular}

Quadro-resumo: "Significativo para o teste não paramétrico Kruskal-Wallis (valor-p =0,000). "Naturezas jurídicas seguidas pela mesma letra não diferem estatisticamente $(\alpha=0,05)$ pelo teste de comparações múltiplas.

Legenda: Gráfico box-plot: $\quad \square$ Md $; \prod_{25 \%}^{75 \%} ; \prod_{\text {Mín. }}^{\text {Máx. }} \quad \begin{aligned} & \text { Md: mediana; } \mathbf{1}^{\circ} \mathbf{Q}_{(1 / 4)}=\mathbf{2 5 \%} \text { : primeiro quartil; } \mathbf{3}^{\circ} \mathbf{Q}_{(3 / 4)}=\mathbf{7 5 \%} \text { : terceiro quartil; } \\ & \text { Máx.: valor máximo; Mín.: valor mínimo; } \mathbf{X}: \text { média e D.P: desvio padrão. }\end{aligned}$

Figura 10 - Gráfico box-plot e quadro-resumo dos testes estatísticos não paramétricos da natureza jurídica em função da proporção dos extremamente pobres.

Por outro lado, quando analisada a atuação das PRIV em termos do indicador renda, verifica-se que essa modalidade de prestação está associada aos municípios com os piores desempenhos quanto às variáveis analisadas. Isso pode ser explicado, conforme discutido anteriormente (Figura 1), pela maior atuação desse tipo de prestador nos municípios localizados na região Norte do Brasil.

Apesar de o Norte abrigar uma das maiores biodiversidades do planeta e ter economia fundamen- 
tada basicamente no extrativismo, por condições históricas foi a região menos favorecida em termos de desenvolvimento econômico e regional. Atualmente, possui o menor Produto Interno Bruto (PIB) do Brasil.

Quando analisadas as características dos municípios operados pelas CESBs e AIMs, verifica-se certa proximidade quanto ao valor de medianas das quatro variáveis que formam o indicador renda.

Conforme discutem Whittington e Hanemann (2011), devido às discrepâncias sociais e econômicas das regiões brasileiras, a gestão das águas deve ser pública e, para tanto, demanda a formulação de um modelo de gestão eficaz, de qualidade e para todos, cujo controle social desejado se concretize por meio da efetiva participação dos usuários. Nesse sentido, os autores são contrários à privatização da prestação dos serviços de abastecimento de água e esgotamento sanitário, uma vez que o saneamento para todos é possível por meio da distribuição de renda e dos subsídios cruzados, o que não é a missão do setor privado, o qual visa ao lucro.

Com base nesse argumento e de acordo com dados obtidos neste trabalho, a atuação das PRIV pode levar ao aumento das discrepâncias de acesso em municípios com maior vulnerabilidade.

Quando analisados os resultados para o IDH-M, conforme a Figura 11, percebem-se diferenças significativas entre as naturezas jurídicas, sendo que AIM apresentou mediana significativamente maior que as demais naturezas.

Nos municípios com IDH-M baixo (inferior a 0,599), quase a totalidade dos domicílios atendidos por rede de água o era por meio da gestão municipal direta ou com sua participação (40\%) ou da gestão estadual (47\%). Por outro lado, os modelos de gestão formados pelas autarquias e PRIV estão associados em maior proporção ao atendimen- to a municípios com médio $(0,600-0,699)$ e alto $(0,700-0,799)$ IDH-M.

Municípios com alto IDH-M apresentam os maiores percentuais de cobertura de sistemas com redes de abastecimento de água e esgotamento sanitário no país (IPEA, 2004). Os municípios classificados como de baixo IDH-M apresentam baixíssimos percentuais de cobertura de rede de esgotos e médios percentuais de cobertura por rede de água. Conforme apontam Rezende et al. (2007), isso reflete a maior universalização do abastecimento de água por redes e o enorme déficit em redes de esgotamento sanitário.

Ao comparar os resultados da natureza jurídica em função do percentual de inadimplência nos últimos 12 meses (Figura 12), verifica-se que o modelo de gestão formado pelas PRIV apresenta menores índices de falta de pagamento das tarifas. Pode-se inferir que a visão empresarial aplicada aos serviços de saneamento está ligada à intenção de substituir o princípio desses serviços como direito social (HELLER; CASTRO, 2007). Tal enfoque requer uma avaliação crítica, uma vez que essa situação envolve princípios mercantilistas, em que os usuários são entendidos como consumidores ou clientes e não como cidadãos portadores de direitos e que demandam esses serviços.

Cabe destacar que, em estudo envolvendo os 625 municípios paulistas, Sanchez (2001) verificou que 330 eram operados por CESB e, dos demais 295 em condições legais de privatizar os sistemas municipalizados, 54 possuíam mais de 50 mil habitantes, porte mínimo para garantir a rentabilidade esperada. Além disso, as autarquias municipais eram pouco endividadas (até mesmo devido à pouca possibilidade de acesso a financiamentos); os níveis de cobertura já instalados eram altos; a modalidade de concessões escolhida era não onerosa (não implicava desembolso imediato por compra de ativos); e, ainda, havia recursos disponíveis para 


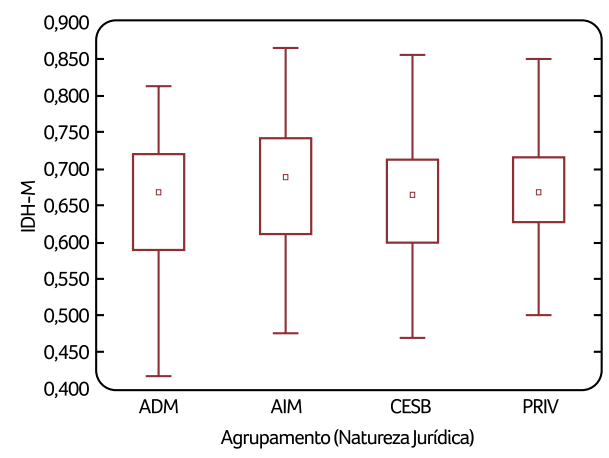

\begin{tabular}{|c|c|c|c|c|c|c|}
\hline \multirow{2}{*}{\multicolumn{2}{|c|}{$\begin{array}{l}\text { Natureza } \\
\text { jurídica\# }\end{array}$}} & \multicolumn{5}{|c|}{ IDH-M * } \\
\hline & & \multirow{2}{*}{$\begin{array}{c}\text { Md } \\
0,688\end{array}$} & \multirow{2}{*}{$\begin{array}{c}\mathbf{1}^{\circ} \mathbf{Q}_{(1 / 4)} \\
0,610\end{array}$} & \multirow{2}{*}{$\begin{array}{c}3^{\circ} \mathbf{Q}_{(3 / 4)} \\
0,740\end{array}$} & \multirow{2}{*}{$\begin{array}{c}\boldsymbol{X} \\
0,679\end{array}$} & \multirow{2}{*}{$\begin{array}{c}\text { D.P. } \\
0,008\end{array}$} \\
\hline AIM & a & & & & & \\
\hline PRIV & $a b$ & 0,668 & 0,630 & 0,720 & 0,668 & 0,006 \\
\hline ADM & b & 0,666 & 0,590 & 0,720 & 0,654 & 0,008 \\
\hline CESB & b & 0,662 & 0,600 & 0,710 & 0,657 & 0,007 \\
\hline
\end{tabular}

Quadro-resumo: "Significativo para o teste não paramétrico Kruskal-Wallis (valor-p =0,000). \#Naturezas jurídicas seguidas pela mesma letra não diferem estatisticamente $(\alpha=0,05)$ pelo teste de comparações múltiplas.

Legenda: Gráfico box-plot: $\quad \square$ Md ; $\prod_{25 \%}^{75 \%} ; \prod_{\text {Mín. }}^{\text {Máx. }} \begin{aligned} & \text { Md: mediana; } \mathbf{1}^{\circ} \mathbf{Q}_{(1 / 4)}=\mathbf{2 5 \%} \text { : primeiro quartil; } \mathbf{3}^{\circ} \mathbf{Q}_{(3 / 4)}=\mathbf{7 5 \%} \text { : terceiro quartil; } \\ & \text { Máx.: valor máximo; Mín.: valor mínimo; } \mathbf{X}: \text { média e D.P: desvio padrão. }\end{aligned}$

Figura 11 - Gráfico box-plot e quadro-resumo dos testes estatísticos não paramétricos da natureza jurídica em função do IDH-M.

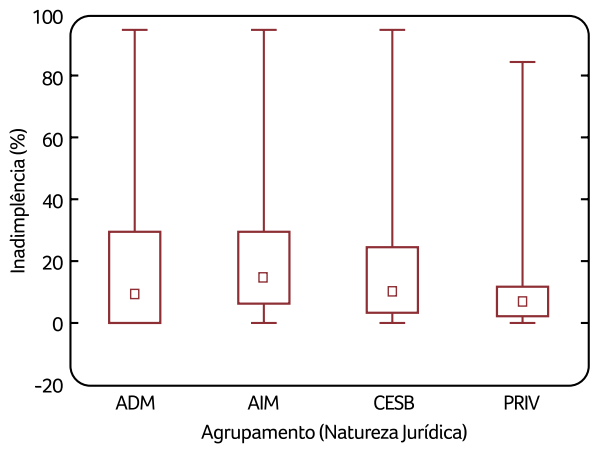

\begin{tabular}{|c|c|c|c|c|c|c|}
\hline \multirow{2}{*}{$\begin{array}{c}\text { Natureza } \\
\text { Jurídica }\end{array}$} & \multicolumn{5}{|c|}{ Inadimplência (\%) * } \\
\cline { 3 - 8 } & & Md & $\mathbf{1}^{\circ} \mathbf{Q}_{(1 / 4)}$ & $3^{\circ} \mathbf{Q}_{(3 / 4)}$ & $\mathbf{X}$ & D.P. \\
\hline AIM & a & 15,00 & 6,00 & 30,00 & 19,92 & 17,70 \\
\hline CESB & b & 10,00 & 3,00 & 25,00 & 15,87 & 16,10 \\
\hline ADM & C & 9,50 & 0,00 & 30,00 & 17,99 & 21,87 \\
\hline PRIV & c & 7,00 & 2,00 & 12,00 & 9,52 & 11,29 \\
\hline
\end{tabular}

Quadro-resumo: "Significativo para o teste não paramétrico Kruskal-Wallis (valor- $p=0,000$ ). "Naturezas jurídicas seguidas pela mesma letra não diferem estatisticamente $(\alpha=0,05)$ pelo teste de comparações múltiplas.

Legenda: Gráfico box-plot: $\quad \square$ Md $; \prod_{25 \%}^{75 \%} ; \prod_{\text {Mín. }}^{\text {Máx. }}$

Md: mediana; $\mathbf{1}^{\circ} \mathbf{Q}_{(1 / 4)}=\mathbf{2 5 \%}$ : primeiro quartil; $\mathbf{3}^{\circ} \mathbf{Q}_{(3 / 4)}=\mathbf{7 5 \%}$ : terceiro quartil; Máx.: valor máximo; Mín.: valor mínimo; $\bar{X}$ : média e D.P: desvio padrão.

Figura 12 - Gráfico box-plot e quadro-resumo dos testes estatísticos não paramétricos da natureza jurídica em função do percentual de inadimplência nos últimos 12 meses.

investimentos por meio do Banco Nacional de Desenvolvimento Econômico e Social (BNDES).

Outro recorte importante para a análise dos déficits de acesso aos serviços de saneamento básico refere-se à renda da população. Zveibil (2003) afirma que a diferença de acesso aos serviços de saneamento, incluindo abastecimento de água, esgotamento sanitário e coleta de resíduos sólidos, segrega os $40 \%$ mais pobres e os $10 \%$ mais ricos, sendo que os maiores déficits na disponibilidade dos serviços concentram-se no primeiro 
segmento. Isso permite traçar uma relação direta entre a renda e a capacidade dessa população de custear os serviços oferecidos.

O índice de perda de faturamento (Figura 13) em cada natureza jurídica foi significativamente diferente dos demais, sendo que CESB apresentou a maior mediana, seguida de PRIV, AIM e ADM, nesta ordem.

Na Figura 14, são apresentados os dados obtidos da natureza jurídica do prestador dos serviços de abastecimento de água em função do número total de economias abastecidas. Verifica-se que as autarquias e as CESBs atuam predominantemente em distritos-sede com maior número de economias abastecidas. Averigua-se, ainda, que o número de economias abastecidas em cada natureza jurídica foi significativamente diferente, sendo que AIM apresentou a maior mediana, seguida de CESB, PRIV e ADM.

Essa constatação pode indicar que ocorre uma preferência por atuação dessas naturezas jurídicas, com vistas à formação de economia de escala, em que os custos médios de longo prazo diminuem ao aumentar a produção, tornando as empresas maiores mais eficientes que as menores, o que pode representar, para o prestador, um maior retorno econômico.

Ao estudar os indicadores de cobertura por serviços de saneamento segundo a taxa de urbanização dos municípios, Toneto e Saiani (2006) verificaram uma tendência de elevação da cobertura, tanto em água quanto em esgoto, à medida que aumenta a taxa de urbanização dos municípios, fato observado em todas as regiões do Brasil, o que sugere maior facilidade de prover os serviços em aglomerações/ concentrações que em populações (domicílios) dispersas - economias de densidade.

Por outro lado, como destacam os mesmos autores, o acesso aos serviços de saneamento está associado à capacidade de pagamento dos habitantes de determinada localidade - por exemplo, pode ser que um domicílio de baixa renda situado em um município de renda elevada tenha acesso mais facilitado aos sistemas de sanea-

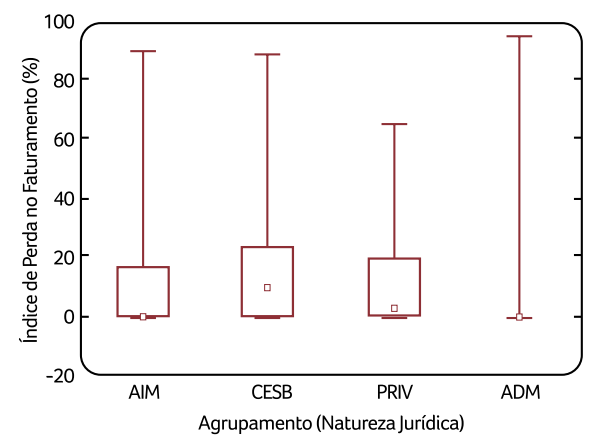

\begin{tabular}{|c|c|c|c|c|c|c|}
\hline \multirow{2}{*}{\multicolumn{2}{|c|}{$\begin{array}{l}\text { Natureza } \\
\text { jurídica" }\end{array}$}} & \multicolumn{5}{|c|}{ Índice de perda de faturamento (\%) * } \\
\hline & & \multirow{2}{*}{$\begin{array}{c}\text { Md } \\
10,00\end{array}$} & \multirow{2}{*}{$\begin{array}{c}1^{\circ} \mathbf{Q}_{(1 / 4)} \\
0,00\end{array}$} & \multirow{2}{*}{$\begin{array}{r}3^{\circ} \mathbf{Q}_{(3 / 4)} \\
24,00\end{array}$} & \multirow{2}{*}{$\begin{array}{c}\mathbf{X} \\
15,27\end{array}$} & \multirow{2}{*}{$\begin{array}{l}\text { D.P. } \\
16,30\end{array}$} \\
\hline CESB & $a$ & & & & & \\
\hline PRIV & b & 3,00 & 0,00 & 20,00 & 10,90 & 14,45 \\
\hline AIM & c & 0,00 & 0,00 & 17,00 & 10,47 & 16,09 \\
\hline ADM & C & 0,00 & 0,00 & 0,00 & 4,58 & 12,98 \\
\hline
\end{tabular}

Quadro-resumo: "Significativo para o teste não paramétrico Kruskal-Wallis (valor-p $=0,000$ ). "Naturezas jurídicas seguidas pela mesma letra não diferem estatisticamente $(\alpha=0,05)$ pelo teste de comparações múltiplas.

Legenda: Gráfico box-plot:

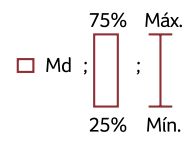

Md: mediana; $\mathbf{1}^{\circ} \mathbf{Q}_{(1 / 4)}=\mathbf{2 5 \%}$ : primeiro quartil; $3^{\circ} \mathbf{Q}_{(3 / 4)}=\mathbf{7 5 \%}$ : terceiro quartil; Máx.: valor máximo; Mín.: valor mínimo; $\mathbf{X}$ : média e D.P: desvio padrão.

Figura 13 - Gráfico box-plot e quadro-resumo dos testes estatísticos não paramétricos da natureza jurídica em função do índice de perda de faturamento. 
mento que uma família com renda maior em um município com renda per capita menor (TONETO; SAIANI, 2006).

Em termos de oferta de serviços de saneamento, Rezende (2005) observa que as soluções individuais ou coletivas adotadas para o abastecimento de água e o esgotamento sanitário estão intrinsecamente associadas aos aspectos do meio físico, como a disponibilidade de recursos hídricos, a distância entre o domicílio e os mananciais de água e a existência de áreas para a disposição dos esgotos.

\section{CONSIDERAÇÕES FINAIS}

O presente estudo buscou compreender determinantes que levam titulares - municípios - a optar por determinado modelo de gestão no abastecimento de água no Brasil. Foram levantadas informações, de 5.493 casos ("distritos-sede"), dos serviços de abastecimento de água, compreendendo, assim, quase a totalidade dos municípios brasileiros. $O$ estudo foi desenvolvido a partir da avaliação comparativa entre os principais modelos de prestação dos serviços de abastecimento de água do Brasil, os quais foram agrupados em ADM, AIM, CESB e PRIV. Para cumprir os objetivos propostos, foram selecionadas 11 variáveis explicativas distribuídas em quatro agrupamentos (geográfico e populacional; renda; desenvolvimento humano e desempenho do prestador).

Assim, visando a verificar a existência de preferência pela adoção de determinado modelo de prestação de serviços de abastecimento de água em função das características dos municípios, foram empregados testes estatísticos não paramétricos univariados, formados pela análise de variância e de comparações múltiplas, e multivariados, compostos pela análise de correspondência

Para todas as variáveis, verificaram-se diferenças estatisticamente significativas (valor- $p<0,05$ ) para o teste univariado não paramétrico de Kruskal-Wallis, que foi seguido do teste de comparações múltiplas.

O presente estudo demonstrou que a natureza administrativa do prestador de serviço possui variações em relação às macrorregiões brasileiras e apresenta diferenças estatisticamente significati-

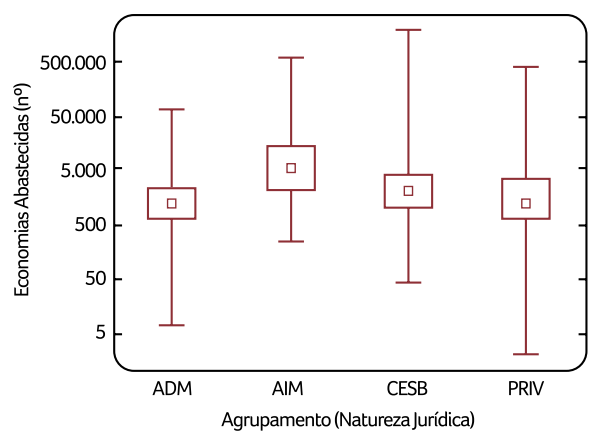

\begin{tabular}{|c|c|c|c|c|c|c|}
\hline \multirow{2}{*}{$\begin{array}{c}\text { Natureza } \\
\text { jurídica" }\end{array}$} & \multicolumn{5}{|c|}{ Economias abastecidas $\left(\mathbf{n}^{\mathbf{0}}\right)$ * } \\
\cline { 3 - 8 } & & Md & $\mathbf{1}^{\circ} \mathbf{Q}_{(1 / 4)}$ & $\mathbf{3}^{\circ} \mathbf{Q}_{(3 / 4)}$ & X & D.P. \\
\hline AIM & a & 5.140 & 2.150 & 14.540 & 17.958 & 44,59 \\
\hline CESB & b & 2.001 & 1.080 & 4.310 & 7.947 & 54,58 \\
\hline PRIV & c & 1.188 & 610 & 3.790 & 9.008 & 36,83 \\
\hline ADM & c & 1.173 & 640 & 2.380 & 2.504 & 4,94 \\
\hline
\end{tabular}

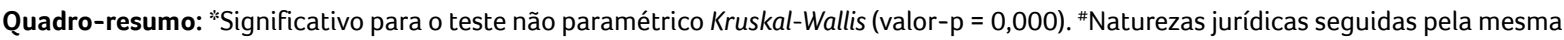
letra não diferem estatisticamente $(\alpha=0,05)$ pelo teste de comparações múltiplas.

Legenda: Gráfico box-plot: $\quad \square$ Md $; \prod_{25 \%}^{75 \%} ; \prod_{\text {Mín. }}^{\text {Máx. }} \begin{aligned} & \text { Md: mediana; } \mathbf{1}^{\circ} \mathbf{Q}_{(1 / 4)}=\mathbf{2 5 \%} \text { : primeiro quartil; } \mathbf{3}^{\circ} \mathbf{Q}_{(3 / 4)}=\mathbf{7 5 \%} \text { : terceiro quartil; } \\ & \text { Máx.: valor máximo; Mín.: valor mínimo; } \mathbf{X}: \text { média e } \text { D.P: desvio padrão. }\end{aligned}$

Figura 14 - Gráfico box-plot e quadro-resumo dos testes estatísticos não paramétricos da natureza jurídica em função do número total de economias abastecidas. 
vas em relação ao porte populacional, ao número total de economias abastecidas e à inadimplência nos últimos 12 meses.

Constatou-se que as autarquias, seguidas pelas CESBs, atuam em cidades mais populosas e com o maior número total de economias abastecidas. Esse fato pode ser explicado pelo fortalecimento desses modelos de gestão e pelos programas e planos do governo, que influenciaram positivamente seus desempenhos econômicos e financeiros.

Por outro lado, o grupo formado por PRIV e ADM apresentou menor índice de inadimplência. $O$ desempenho das PRIV pode ser explicado pelo provável pressuposto do ganho financeiro visado pelo capital privado. Nesse sentido, é preciso que o agente público e titular dos serviços de saneamento assuma que tais serviços representam um direito essencial da população.

Cabe ressaltar que a participação do poder público no fornecimento, financiamento e intervenções nas ações de saneamento representa uma questão de soberania e interesse institucional. Afinal, são serviços essenciais para a população e constituem monopólios naturais. Assim, a participação da prestação privada dos serviços, que, no Brasil, abrange $4,51 \%$ do total de distritos-sede, parece ser pouco relevante em termos de desempenho e pertinência nos países em desenvolvimento, como afirmam alguns autores.

Em função da variedade de modelos existentes para a gestão dos serviços de saneamento nos municípios brasileiros, a escolha do modelo para determinado município pode gerar alguns conflitos. Há casos em que alguns municípios tendem a delegar os serviços pela sua insustentabilidade financeira e, em outras situações, há disputas entre entes federativos ou empresas pela conquista do direito de prestá-los. Fatores como o capital político e financeiro envolvido na prestação do serviço podem explicar, em geral, tais disputas.

\section{AGRADECIMENTOS}

Os autores agradecem ao Conselho Nacional de Desenvolvimento Científico e Tecnológico (CNPq) pela concessão do auxílio - bolsa de estudo de doutorado (GD) e de iniciação científica (IC) -, ao primeiro e segundo autores e pelo financiamento do projeto de tese aprovado junto ao Edital Universal (Processo 475638/2012-3) e ao PPGSMARH da UFMG.

\section{REFERÊNCIAS}

ASSOCIAÇÃO BRASILEIRA DAS CONCESSIONÁRIAS PRIVADAS DE SERVIÇOS PÚBLICOS DE ÁGUA E ESGOTO (ABCON) E SINDICATO NACIONAL DAS CONCESSIONÁRIAS PRIVADAS DE SERVIÇOS PÚBLICOS DE ÁGUA E ESGOTO (SINDCON). Panorama da participação privada no Saneamento Brasil 2014. 66p.

BESSA, E.S. Saneamento e Cidadania: privatização, municipalização e mecanismos de controle. 326 p. Tese (Doutorado Serviço Social) Programa de Pós-Graduação da Escola de Serviço Social da Universidade Federal do Rio de Janeiro, Rio de Janeiro, 2006. 326p.

BRASIL. Lei 11.445, de 5 de janeiro de 2007. Estabelece diretrizes nacionais para o saneamento básico. Brasília: Diário Oficial [da] República Federativa do Brasil, Poder Executivo, Brasília, DF, 08 jan. de 2007. Seção 1. p. 3. Disponível em: https://www.planalto. gov.br/ccivil_03/_ato2007-2010/2007/lei/l11445.htm. Acesso em: 01 jun. 2011.

CAMPOS, H.K.T.; MONTENEGRO, M.H.F. Sistema Nacional de Informações em Saneamento Básico/SINISA: caderno temático $\mathrm{n}^{\circ} 7$. In: REZENDE, S.C. (Org.). Cadernos temáticos. Brasília: Ministério das Cidades, 2011. (Panorama do Saneamento Básico no Brasil, v. 7). No prelo.

COSTA, A. M. Avaliação da política nacional de saneamento, Brasil - 1996/2000. 2003. 248p. Tese (Doutorado em Saúde Pública) Centro de Pesquisas Aggeu Magalhães, Escola Nacional de Saúde Pública, Fundação Oswaldo Cruz, Recife. 2003.

HALL, D; LOBINA, E. Public policy options for financing sewerage systems. In: CASTRO, J. E. \& HELLER, L. (Edit). Water and Sanitation Service: public policy and management. United Kingdom: Earthscan, 2009, pp. $104-121$.

HELLER, L.; COUTINHO, M. L.; MINGOTI, S. Diferentes modelos de gestão de serviços de saneamento produzem os mesmos resultados? Um estudo comparativo em Minas Gerais com base em indicadores. Engenharia Sanitária e Ambiental, v. 11, p. 325-336, 2006.

HELLER, L., CASTRO, J. E. Política pública de saneamento: apontamentos teórico-conceituais. Engenharia Sanitária e Ambiental, v. 13, n.3, p. 284-295, 2007. 
HELLER, P. G. B.; VON SPERLING, M.; HELLER, L. Desempenho tecnológico dos serviços de abastecimento de água e esgotamento sanitário em quatro municípios de Minas Gerais: uma análise comparativa. Engenharia Sanitária e Ambiental, v.14, n.1, p. 109118, jan/mar 2009.

HELLER, P. G. B. Modelos de prestação dos serviços de abastecimento de água e esgotamento sanitário: uma avaliação comparativa do desempenho no conjunto dos municípios brasileiros. $125 \mathrm{f}$. Tese (Doutorado em Saneamento, Meio Ambiente e Recursos Hídricos) - Escola de Engenharia, Universidade Federal de Minas Gerais, Belo Horizonte, 2012.

INSTITUTO BRASILEIRO DE GEOGRAFIA E ESTATÍSTICA (IBGE). Pesquisa Nacional de Saneamento Básico - 2008. IBGE, Rio de Janeiro, RJ, 2010. 219p.

INSTITUTO BRASILEIRO DE GEOGRAFIA E ESTATÍSTICA (IBGE). Banco de Dados Agregados. Sistema IBGE de Recuperação Automática (SIDRA). Disponível em: http://www.ibge.gov.br. Acesso em: 20 dez. 2013.

INSTITUTO DE PESQUUISA ECONÔMICA APLICADA (IPEA). Objetivos de Desenvolvimento do Milênio: Relatório nacional de acompanhamento. Brasília: Ipea, 2004. 96p.

INSTITUTO TRATA BRASIL. Benefícios econômicos da expansão do saneamento brasileiro. Fundação Getúlio Vargas e Instituto Brasileiro de Economia. 2010. 32p.

LOUREIRO, A. L. Gestão dos serviços de abastecimento de água e esgotamento sanitário: análise de diferentes modelos, 2009. 188f. Dissertação (Mestrado em Engenharia Ambiental Urbana) Escola Politécnica, Universidade Federal da Bahia, Salvador, 2009.

MAGALHÃES, T. Manejo de resíduos sólidos: sustentabilidade e verdade orçamentária com participação popular. In: Brasil. Ministério das Cidades. Secretaria Nacional de Saneamento Ambiental. CORDEIRO, B. S. (Coord.). Prestação dos serviços públicos de saneamento básico. Brasília, 2009, p. 520 - 530.

OGERA, R. C.; PHILIPPI JR., A. Gestão dos serviços de água e esgoto nos municípios de Campinas, Santo André, São José dos Campos e Santos, no período de 1996 a 2000. Engenharia Sanitária e Ambiental, v. 10, n.1, p.72-81, jan/mar 2005.

ORGANIZATION UNITED NATIONS (ONU). Resolutions n64/292: The human right to water and sanitation. Resolution adopted by the General Assembly. 108th plenary meeting 28 July 2010. Disponível em: www.un.org/ga/search/view_doc.asp?symbol=A/ RES/64/292. Acesso em: 02 fev. 2012.
PROGRAMA DAS NAÇÕES UNIDAS PARA O DESENVOLVIMENTO (PNUD), INSTITUTO DE PESQUISA ECONÔMICA APLICADA (IPEA) E FUNDAÇÃO JOÃO PINHEIRO (FJP). Atlas do desenvolvimento humano no Brasil: dados brutos. Arquivo (29,73 Megabytes). Arquivo Excel 2007. Disponível em: http://www.atlasbrasil.org. br/2013/pt/download/.

REZENDE, S. Aspectos demográficos da cobertura de serviços de saneamento no Brasil urbano contemporâneo. 2005. 153 p. Tese (doutorado em Demografia do Centro de Desenvolvimento e Planejamento Regional do Centro de Desenvolvimento e Planejamento Regional) - Faculdade de Ciências Econômicas da Universidade Federal de Minas Gerais, Belo Horizonte, 2005.

REZENDE, S.C.; WAJNMAN, S.; CARVALHO, J. A. M.; HELLER, L. Integrando oferta e demanda de serviços de saneamento: análise hierárquica do panorama urbano brasileiro no ano 2000. Engenharia Sanitária e Ambiental, v. 12, n.1, p.90 - 101, jan/mar 2007.

REZENDE, S. C.; HELLER, L. O saneamento no Brasil: políticas e interfaces. 2. ed. rev. e ampl. Belo Horizonte: UFMG, 2008. 387 p.

SANCHEZ, O. A. privatização do saneamento. São Paulo Perspectiva, v. 15, n. 1, p. 89-101, 2001.

SOUSA, A.C.A. Política de Saneamento no Brasil: atores, instituições e interesses. Tese (Ciências na área de Saúde Pública). FIOCRUZ. Rio de Janeiro 2011. 88p.

SIEGEL, S.; CASTELLAN, N. J. Nonparametric statistics for the behavioral sciences. 2. ed. New York: McGraw-Hill, 1988.

STATSOFT, Inc.(versão 8.0) [Programa de computador]. Tulsa, USA: Statsoft, Inc., 2007.

TONETO, R.j; SAIANI, C.C. Restrições à Expansão dos Investimentos no Saneamento Básico Brasileiro. Revista Econômica do Nordeste, Fortaleza, v. 37, nº 4, out-dez. 2006.

WHITTINGTON D.; HANEMANN W. M. The economic costs and benefits of investments in municipal water and sanitation infrastructure: a global perspective. February, Department of Agricultural and Resource Economics, UCB, CUDARE Working Paper 1027. 2011.38p.

ZVEIBIL, V.Z. Reforma do Estado e a Gestão do Saneamento: uma trajetória incompleta. 2003. 237 p. Tese (Ciências na área de Saúde Pública). Escola Nacional de Saúde Pública. Fundação Oswaldo Cruz. Rio de Janeiro. 2005. 237p. 